\title{
Structure Prediction and Enzymatic Properties of Phytase phyS
}

\author{
Yueming $\mathrm{Li}^{1}$, Hongqing $\mathrm{Xu}^{2}$, Jianchun $\mathrm{Xu}^{1}$, Ruilian Pang ${ }^{3}$, Bingzheng $\mathrm{Xu}^{1}$ \\ ${ }^{1}$ Qingdao Langyatai Group Co., Ltd., Qingdao, China \\ ${ }^{2}$ Qingdao West Coast New Area Agricultural and Rural Bureau, Qingdao, China \\ ${ }^{3}$ Qingdao West Coast New Area Market Supervision and Administration Bureau, Qingdao, China \\ Email: benniu2004@163.com
}

How to cite this paper: Li, Y.M., Xu, H.Q. $\mathrm{Xu}$, J.C., Pang, R.L. and Xu, B.Z. (2019) Structure Prediction and Enzymatic Properties of Phytase phyS. Advances in Enzyme Research, 7, 57-65.

https://doi.org/10.4236/aer.2019.74005

Received: December 5, 2019

Accepted: December 21, 2019

Published: December 24, 2019

Copyright (c) 2019 by author(s) and Scientific Research Publishing Inc. This work is licensed under the Creative Commons Attribution International License (CC BY 4.0).

http://creativecommons.org/licenses/by/4.0/

\section{(c) (i) Open Access}

\begin{abstract}
Phytase is a kind of enzyme that hydrolyzes phytic acid and its salts to produce inositol and phosphoric acid. As a new feed additive, phytase has great potential in animal nutrition and environmental protection. Because of its good stability, large-scale production and high activity, microbial phytase has become a hot spot in industrial application. Here, we reported the predicted structure and enzymatic properties of a phytase from Bacillus subtilis, which was named as phyS. It was clear that the optimal temperature is $35^{\circ} \mathrm{C}$, and the optimal pH is 8 . Meanwhile, the enzyme activity was kept at above $90 \%$ in the range of $\mathrm{pH} 8-9$, this result demonstrated that phyS is an alkaline phytase. This study lays a foundation for the extensive application of phys.
\end{abstract}

\section{Keywords}

Structural Prediction, Enzymatic Properties, Phytase

\section{Introduction}

Feed industry is one of the top ten basic industries in China's national economy. Feed enzyme preparation has attracted more and more attention because it is widely used in the fields of improving the production performance of animals and controlling the pollution of excrement [1]. Phytase, also known as myo inositol hexaphosphohydrolase, is a kind of Phosphohydrolase which can hydrolyze ester bond. Phytase has a special spatial structure, which can separate phosphorus from phytic acid molecules in turn, degrade phytic acid into inositol and inorganic phosphorusand release other nutrients combined with phytic acid, which can be used for animal growth and development [2]. Phytase can improve animal production performance, reduce production costs, reduce environmental 
pollution, and has a wide range of application value.

Phytase has a wide range of sources. It is found in plants, animals, fungi, yeast and bacteria. Due to the characteristics of microbial phytase, such as wide range of action, good stability, easy to scale production, high activity and short growth cycle, it has become the focus of research [3]. Since the first phytase (from $A s$ pergillus terreus no. 9a1) has been isolated and purified, a variety of acidase producing bacteria have been found, such as Bacillus subtilis, Pseudomonas, Escherichia coli, Lactobacillus, Klebsiella, Aspergillus niger, Aspergillus oryzae, Rhizopus, yeast and so on [4] [5]. According to the structure and catalytic mechanism, phytase can be divided into histidine acid phosphatase (HAP), $\beta$-foldable barrel phytase (BPP), cysteine phosphatase phytase (CP) and purple acid phosphatase phytase (PAP) [6]. BPP has a special folding bucket structure in its molecular structure, so it gets its name. This kind of phytase was first found in Bacillus [7], most of the BPP found at present still comes from Bacillus [8] [9] [10] which is the only neutral partial alkaline phytase ( $\mathrm{pH} 6.0$ - 8.0) in the phytase. Compared with HAP, BPP has higher thermal stability, is easier to degrade phytic acid, and is more suitable for neutral and alkaline environment. Some studies have shown that BPP is the most widely distributed in land and water environment. Therefore, BPP has greater social demand and market promotion prospects. However, due to the low specific activity of BPP and the difficulty of separation and purification, the industrialization of BPP is limited. Obtaining BPP with higher enzyme activity is the urgent task for its commercial production.

In this study, we successfully studied the bioinformatics of phyS from Bacillus subtilis, constructed the structure, defined the catalytic domain, and studied the properties of enzymes, which laid the foundation for clarifying the biological characteristics of phys.

\section{Material and Methods}

\subsection{Search and Comparison of Homologous Sequences}

Through the search tool of BLASTP (https://blast.ncbi.nlm.nih.gov/), it is found that five sequences in PDB database have homology with phyS, and the similarity between them is not less than $95 \%$. It is worth mentioning that among the searched homologous sequences, pdbid: 1 POO [11], pdbid: 1 QLG [11], pdbid: 3 AMR [12] and 1 CVM are all 3-phytase, so it's reasoned that phyS is 3-phytase. Meanwhile, the crystal structures of these four homology proteins were selected as the template Formwork construction. ClustalW, a multi sequence alignment program, was used to perform multi sequence alignment for the above sequences, and the default setting of parameters were selected. Then, based on the prediction results of the secondary structure of DSSP, the results are fine tuned by comparison. The result graph of sequence alignment is completed on the online server of espript 2.2 [13]. The protein structure is displayed by the graphic software PyMOL [14]. 


\subsection{Homologous Modeling and Model Evaluation}

The tertiary structure of phyS was constructed by SWISS-MODEL [15]. Using the optimization program and scoring program of modeller to optimize and sort the generated structures, and finally output the structure model in the top 5 in PDB format. In order to avoid the deviation of the results caused by the preliminary scoring, we select PROCHECK [16] and verify 3D [17] to further evaluate the quality of the generated models.

\subsection{The Main Enzyme Characteristics of phyS}

Determination of phytase activity: the method for determination of phytase activity is ferrous sulfate molybdenum blue method [18]. Take $100 \mu$ phys solution, incubate it in $37^{\circ} \mathrm{C}$ water bathed for $5 \mathrm{~min}$, add $400 \mu \mathrm{l}$ substrate phytic acid sodium solution, and react in $37^{\circ} \mathrm{C}$ water bathed for $15 \mathrm{~min}$. Add $500 \mu \mathrm{l}$ of termination solution to terminate the reaction. Add $500 \mu \mathrm{l}$ developer, leave it at room temperature for $10 \mathrm{~min}$, make it fully develop color, with the temperature of $37^{\circ} \mathrm{C}$ centrifugate it at the speed of $4000 \mathrm{r} / \mathrm{min}$ for $10 \mathrm{~min}$, remove some invisible precipitated impurities, and measure the OD value of the solution at 700 $\mathrm{nm}$ wavelength. A control experiment was set up. In the control group, $100 \mu \mathrm{l}$ phytase solution was first added to $500 \mu$ termination solution to inactivate the enzyme, and then the same method was used for subsequent determination.

Determination of the optimum reaction temperature: the enzyme activity of phyS was determined by enzymatic reaction of phyS protein solution in buffer system with $\mathrm{pH}$ of 8.0 and at different temperatures $\left(10^{\circ} \mathrm{C}-65^{\circ} \mathrm{C}\right)$.

Determination of optimum pH: under the optimum temperature, the solution of phys was used for enzymatic reaction under the condition of $\mathrm{pH} 3.0-9.0$ to determine the enzyme activity of phys.

Measurement of temperature tolerance: phyS was incubated at different temperatures $\left(20^{\circ} \mathrm{C}-65^{\circ} \mathrm{C}\right)$ for different times, and then immediately cooled in ice. The enzyme activity of phyS was measured under the optimum reaction conditions

$\mathrm{pH}$ stability: after treating phyS in a series of different $\mathrm{pH}$ buffers for $30 \mathrm{~min}$, the enzyme activity of phys was determined under the optimum temperature and $\mathrm{pH}$ condition.

Determination of Michaelis constant and maximum reaction rate ( $\mathrm{Km}$ value, $\left.\mathrm{V}_{\max }\right)$ : prepare different concentrations $(0.1 \mathrm{mmol} / \mathrm{L}-10.0 \mathrm{mmol} / \mathrm{L})$ of substrate solution, and determine the enzyme activity of phyS under the optimum reaction conditions. The apparent $\mathrm{Km}$ and $\mathrm{V}_{\max }$ are calculated by the method of line weave burk double reciprocal curve [19].

\section{Results and Discussion}

\subsection{Sequence Analysis of phyS}

The recombinant plasmid containing pet-28b-phys stored in the laboratory was sequenced, and the protein sequence was measured to have 373 residues. Color alignment was conducted on clustalw server. From the comparison results 
(Figure 1), we can see that the sequence identity of phyS with 1PO0, 1QLG, $3 \mathrm{AMR}$ and $1 \mathrm{CVM}$ was about $95 \%$, and not identity region is mainly concentrated in the first 29 residues at the n-terminal. Therefore, it is effective and credible to construct the tertiary structure of phyS with the above four proteins as templates. Meanwhile, by using the online server of swiss-model, sites of L71, L80, Y83L85, R76, V101, E187, D211, L227, I258, D288, T279, D336, H342, Q367-N369 and D379 were predicted as the interaction sites of $\mathrm{Ca}^{2+}$. The interactions were shown in Figure 2(b).

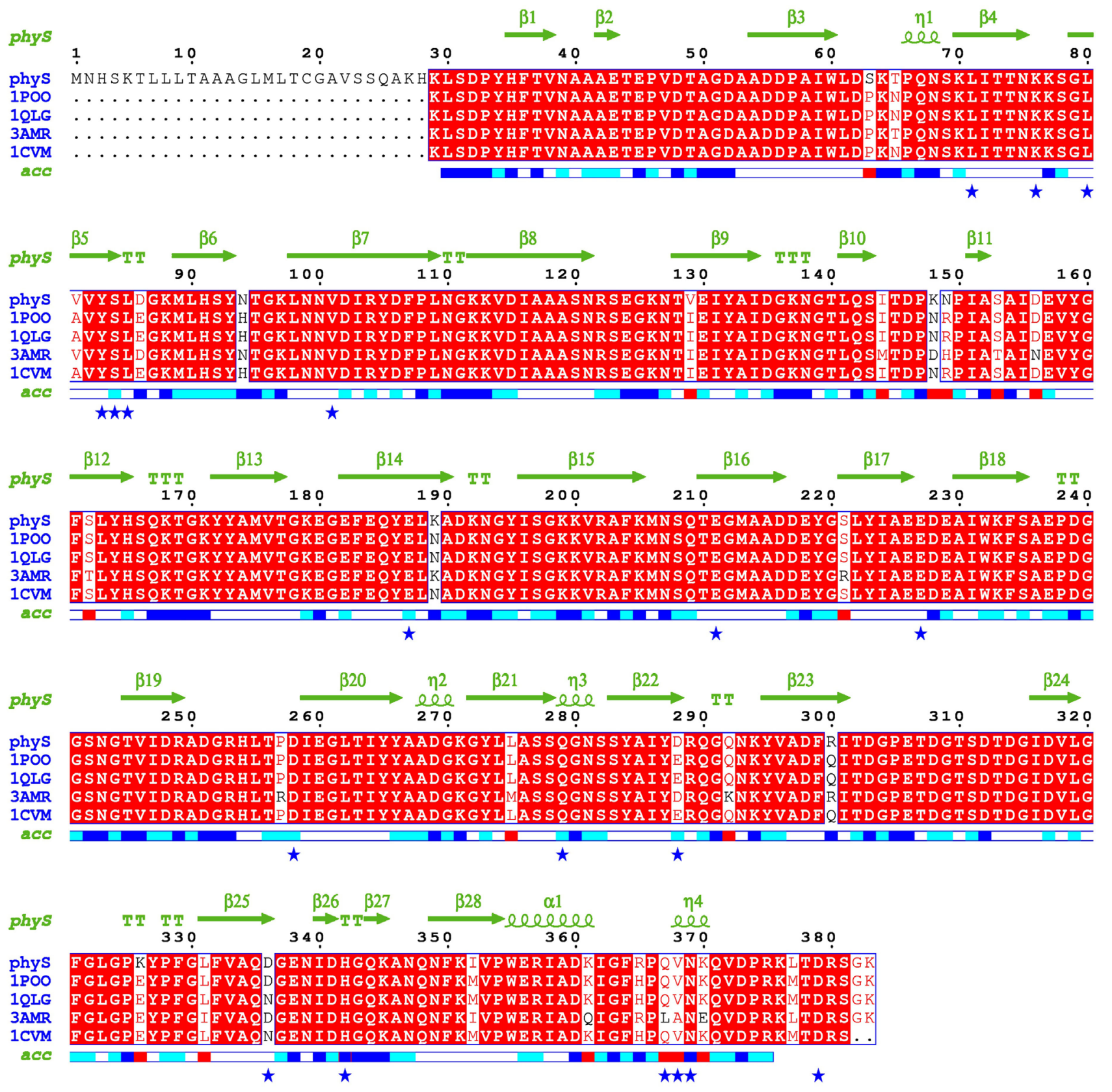

Figure 1. Sequence alignment for phyS and its homology structures. Secondary structure elements for phyS are indicated in green. The predicted sites that interact with $\mathrm{Ca}^{2+}$ is marked as blue stars. The presentation of the sequence alignment is made using the online service of ESPript 2.2. 


\subsection{Homologous Modeling and Model Evaluation}

The tertiary structure of phyS was constructed by using the homologous modeling program SWISS-MODEL [15]. By using the optimization program and scoring program of SWISS-MODEL, the generated structure is preliminarily optimized and sorted, and finally the structure model ranking in the top 5 is output in PDB format. The structure of phys belongs to five-blade $\beta$-propeller family, each blade was formed by four $\beta$-strands (Figure 3). In order to avoid the deviation of the results caused by the preliminary scoring, we select PROCHECK [16] and verify 3D [17] to further evaluate the quality of the generated model.

Through the analysis of Ramachandran map (Figure 4(a)) showed that $89.9 \%$ of the $\Phi$ and $\psi$ corners of the model protein residues are in the best region, 9.1\% of the residues fall into other licensing areas, $0.6 \%$ fall in the barely licensed areas, $0.4 \%$ of the residues fall in the disallowed areas. The above results show that the dihedral angle of module construction is very reasonable. At the same time, using profile_3D (Figure 4(b)), it is not difficult to find that except for V101, the scores of all other residues are greater than that of other residues, and the scores of all other residues are greater than 0 , and the average $3 \mathrm{D}-1 \mathrm{D}$ scores of $99.7 \%$ of the residues are greater than 0.2 , which indicates that the side chain environment is acceptable.

\subsection{Major Enzymatic Characteristics of phyS}

\subsubsection{Optimal Reaction Temperature of phyS}

The results of phyS determination at different temperatures showed (Figure 5(a)) that the optimal reaction temperature of the enzyme was $35^{\circ} \mathrm{C}$, and the catalytic activity of the enzyme remained above $30 \%$, at $10^{\circ} \mathrm{C}-45^{\circ} \mathrm{C}$, indicating that phys could play its catalytic activity in a wide range of temperature.

(a)

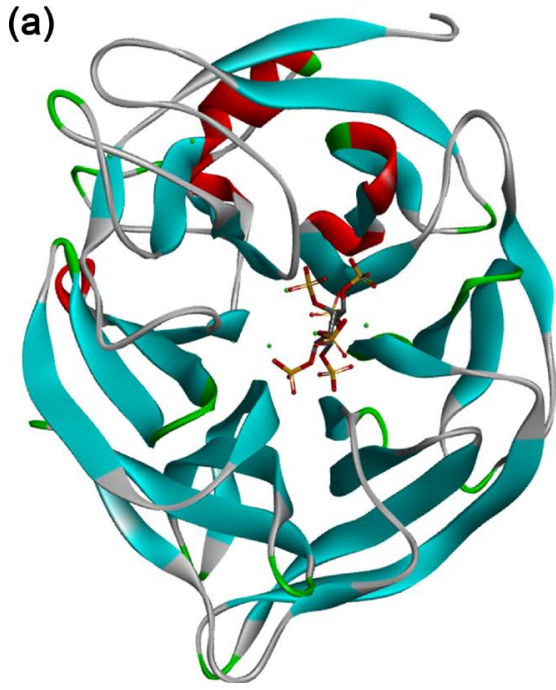

(b)

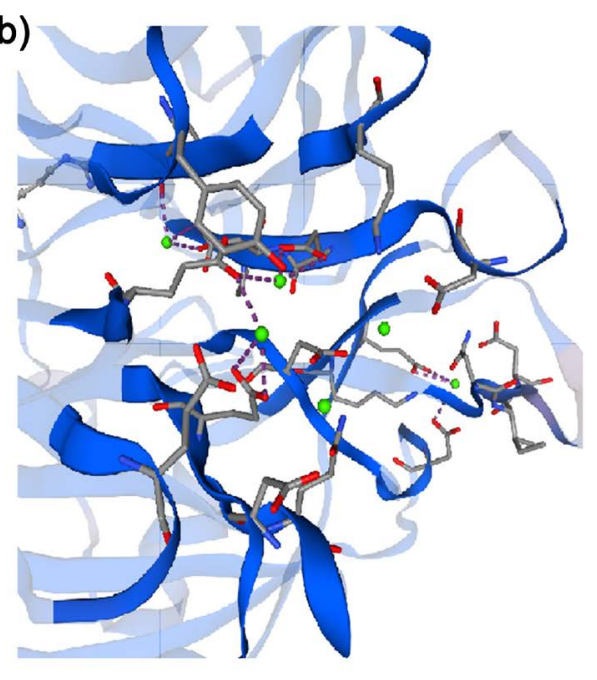

Figure 2. The tertiary structure (a) and interaction sites of phyS and $\mathrm{Ca}^{2+}$ (b) the structure was shown in cartoon by pymol and the interaction was shown in sticks, $\mathrm{Ca}^{2+}$ were shown in green dots. 




Figure 3. Schematics of phyS structure. The structure was generated by Pymol and it was shown in cartoon. The $\beta$-strands are represented by arrows and helices as coils.

(a)

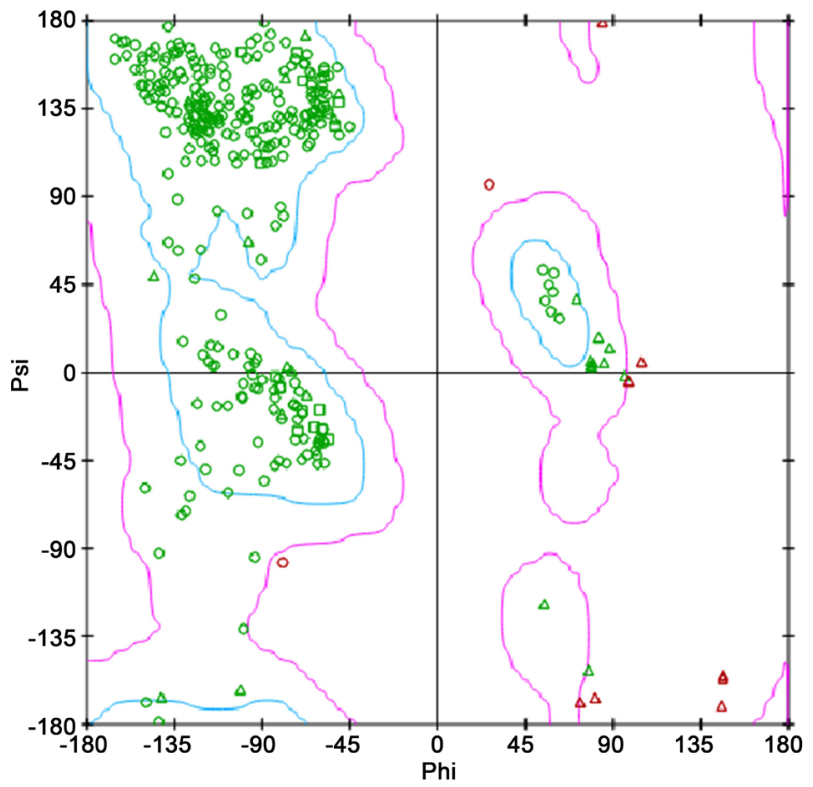

(b)

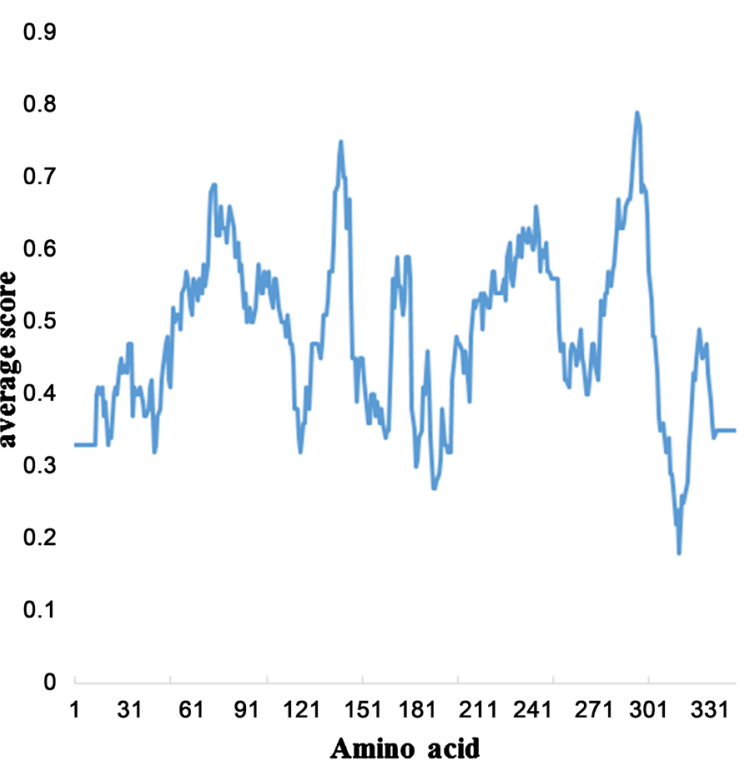

Figure 4. (a) Main-chain dihedral angles (Ramachandran plot) and (b) the Verify_3D plots of modeling phyS.

\subsubsection{Optimal pH of phyS}

phyS keeps a good catalytic activity in $\mathrm{pH} 5$ - 9. With the increase of $\mathrm{pH}$ value, the enzyme activity increases also, and then reaches the peak at $\mathrm{pH}$ 8.0. Furthermore, with the increase of $\mathrm{pH}$ value, the enzyme activity begins to decline. The optimal $\mathrm{pH}$ is 8.0 , which indicates that phyS belongs to alkaline phytase. When the $\mathrm{pH}$ is less than 4 , the catalytic activity of the enzyme is reduced to less than 

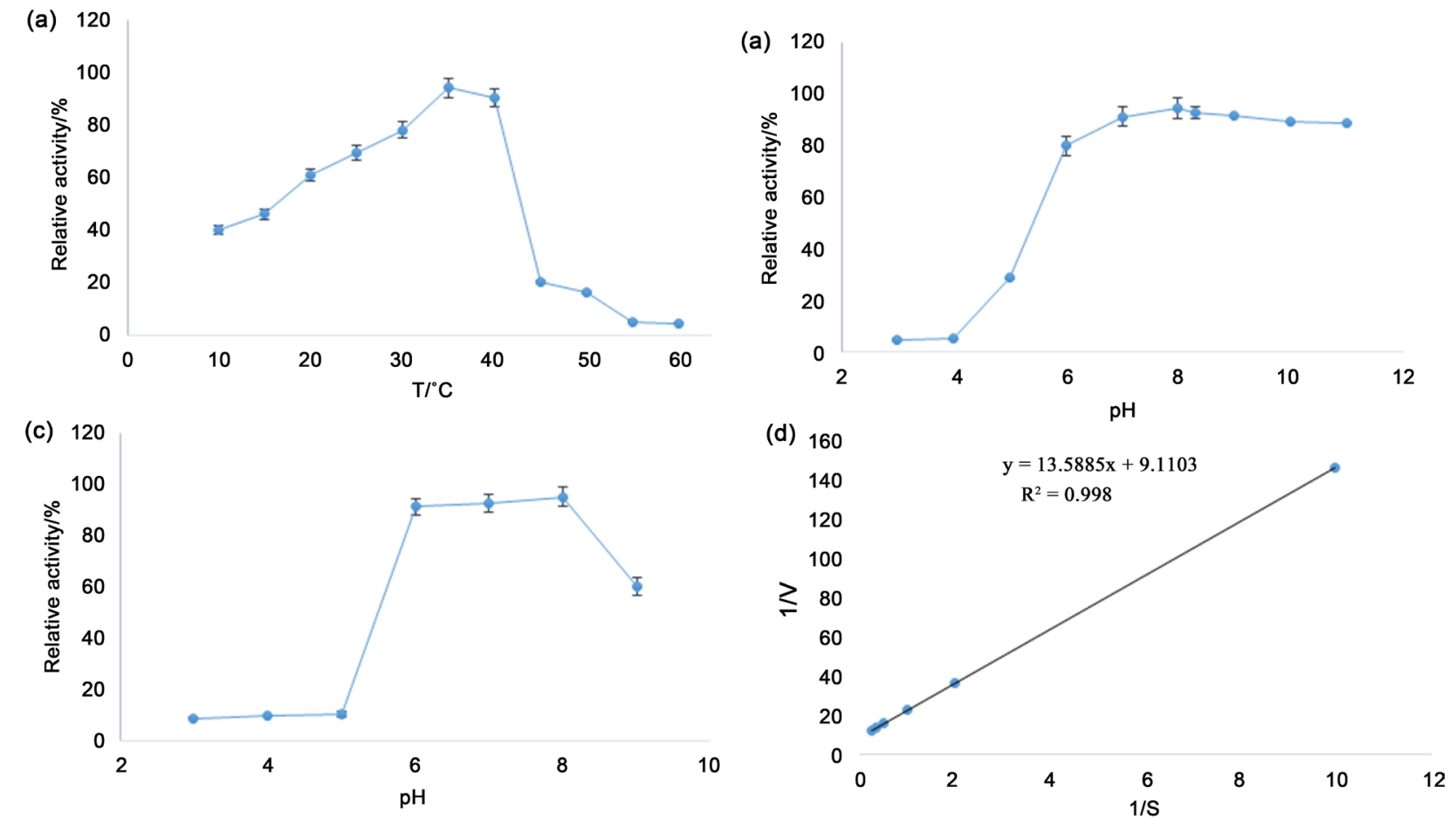

Figure 5. Enzymatic properties of phyS. (a) The optimal temperature of phys; (b) The optimal pH of phys; (c) pH stability of phys; (d) Kinetic parameters of enzymatic reaction. Error bars represents the standard deviations.

$10 \%$ (Figure $5(\mathrm{~b})$ ), this result indicate that phys is not suitable to work in a strong acid environment.

\subsubsection{Temperature Stability of Phyht}

After incubation for $15 \mathrm{~min}$ at $60^{\circ} \mathrm{C}$, the enzyme activity of phyS decreased to less than $15 \%$, indicating that the enzyme activity of phyS can't be well maintained when the temperature is higher than $60^{\circ} \mathrm{C}$. When the temperature is at $45^{\circ} \mathrm{C}$, the phytase activity can still maintain $80 \%$ after incubation for 2 hours. When the temperature was less than $37^{\circ} \mathrm{C}$, the activity of phytase was almost unchanged within 5 hours. It shows that the stability of phyS is better at low temperature.

\subsection{4. pH Stability of phyS}

When phyS is treated in a series of different $\mathrm{pH}$ buffers for $30 \mathrm{~min}$ at $37^{\circ} \mathrm{C}$, and the $\mathrm{pH}$ is $6-12$, the activity of the remaining enzyme remains above $95 \%$. When the $\mathrm{pH}$ is lower than 6 , the enzyme activity drops rapidly. When the $\mathrm{pH}$ is lower than 4 , there is almost no enzyme activity (Figure $5(c)$ ), indicating that the enzyme has good alkali resistance but poor acid resistance.

\subsubsection{Kinetic Parameters of phyS Reaction}

As shown in Figure 5(d), the apparent $\mathrm{Km}$ and $V_{\max }$ are calculated to be 1.38 $\mathrm{mmol} / \mathrm{L}$ and $100.06 \mu \mathrm{mol} /(\mathrm{mg} \cdot \mathrm{min})$, respectively, under the condition of sodium phytate as the substrate, through the drawing of line weave burk double reciprocal curve [20]. 


\section{Conclusion}

In this study, phyS was taken as the research object. Sequence analysis and structure prediction were carried out and the basic enzymatic characteristics of phyS were defined. Its main structural characteristics were understood through structure prediction, which laid a foundation for further study of phyS structure and explanation of the relationship between function and structure. The enzymatic properties were studied. The main catalytic properties of phyS were explained, which provided a theoretical basis for the extensive application in the future.

\section{Conflicts of Interest}

The authors declare no conflicts of interest regarding the publication of this paper.

\section{References}

[1] Mrudula, V.U., Jaiswal, A.K., Krishna, S. and Pandey, A. (2019) Thermostable Phytase in Feed and Fuel Industries. Bioresource Technology, 278, 400-407. https://doi.org/10.1016/j.biortech.2019.01.065

[2] Li, X., Yang, H., Hu, J., Wu, Y., Li, J. and Ren, Y. (2010) Diversity and Classification of Phytases. Microbiology China, 37, 738-747.

[3] Dvorakova, J. (1998) Phytase: Sources, Preparation and Exploitation. Folia Microbiologica (Praha), 43, 323-338. https://doi.org/10.1007/BF02818571

[4] Liu, N., et al. (2008) Effect of Diet Containing Phytate and Phytase on the Activity and Messenger Ribonucleic Acid Expression of Carbohydrase and Transporter in Chickens. Journal of Animal Science, 86, 3432-3439. https://doi.org/10.2527/jas.2008-1234

[5] Reddy, N.R., Sathe, S.K. and Salunkhe, D.K. (1982) Phytates in Legumes and Cereals. In: Chichester, C.O., Mrak, E.M. and Stewart, G.F., Eds., Advances in Food Research, Academic Press, Cambridge, 1-92. https://doi.org/10.1016/S0065-2628(08)60110-X

[6] Lim, B.L., Yeung, P., Cheng, C. and Hill, J.E. (2007) Distribution and Diversity of Phytate-Mineralizing Bacteria. The ISME Journal, 1, 321-330.

https://doi.org/10.1038/ismej.2007.40

[7] Kerovuo, J., Lauraeus, M., Nurminen, P., Kalkkinen, N. and Apajalahti, J. (1998) Isolation, Characterization, Molecular Gene Cloning, and Sequencing of a Novel Phytase from Bacillus subtilis. Applied and Environmental Microbiology, 64, 2079-2085.

[8] Huang, H., Shi, P., Wang, Y., Luo, H., Shao, N., Wang, G., et al. (2009) Diversity of Beta-Propeller Phytase Genes in the Intestinal Contents of Grass Carp Provides Insight into the Release of Major Phosphorus from Phytate in Nature. Applied and Environmental Microbiology, 75, 1508-1516. https://doi.org/10.1128/AEM.02188-08

[9] Zhang, R., Yang, P., Huang, H., Yuan, T., Shi, P., Meng, K., et al. (2011) Molecular and Biochemical Characterization of a New Alkaline $\beta$-Propeller Phytase from the Insect Symbiotic Bacterium Janthinobacterium sp. TN115. Applied Microbiology and Biotechnology, 92, 317-325. https://doi.org/10.1007/s00253-011-3309-0

[10] Gulati, H.K., Gulati, H.K., Chadha, B.S., Chadha, B.S., Saini, H.S. and Saini, H.S. (2007) Production and Characterization of Thermostable Alkaline Phytase from 
Bacillus laevolacticus Isolated from Rhizosphere Soil. Journal of Industrial Microbiology \& Biotechnology, 34, 91-98. https://doi.org/10.1007/s10295-006-0171-7

[11] Kim, H., Oh, T., Kim, Y., Shin, S., Oh, B., Oh, B., et al. (2000) Crystal Structures of a Novel, Thermostable Phytase in Partially and Fully Calcium-Loaded States. Nature Structural Biology, 7, 147-153.

[12] Zeng, Y., Ko, T., Lai, H., Cheng, Y., Wu, T., Ma, Y., et al. (2011) Crystal Structures of Bacillus Alkaline Phytase in Complex with Divalent Metal ions and Inositol Hexasulfate. Journal of Molecular Biology, 409, 214-224.

https://doi.org/10.1016/j.jmb.2011.03.063

[13] Gouet, P., Robert, X. and Courcelle, E. (2003) ESPript/ENDscript: Extracting and Rendering Sequence and 3D Information from Atomic Structures of Proteins. Nucleic Acids Research, 31, 3320-3323. https://doi.org/10.1093/nar/gkg556

[14] Lilkova, E., Petkov, P., Ilieva, N. and Litov, L. (2015) The PyMOL Molecular Graphics System. 10919-25.

[15] Schwede, T., Kopp, J., Guex, N. and Peitsch, M.C. (2003) SWISS-MODEL: An Automated Protein Homology-Modeling Server. Nucleic Acids Research, 31, 3381-3385. https://doi.org/10.1093/nar/gkg520

[16] Laskowski, R.A., MacArthur, M.W., Moss, D.S. and Thornton, J.M. (1993) PROCHECK: A Program to Check the Stereochemical Quality of Protein Structures. Journal of Applied Crystallography, 26, 283-291. https://doi.org/10.1107/S0021889892009944

[17] Eisenberg, D., Luthy, R. and Bowie, J.U. (1997) VERIFY3D: Assessment of Protein Models with Three-Dimensional Profiles. Methods in Enzymology, 277, 396-404. https://doi.org/10.1016/S0076-6879(97)77022-8

[18] Choi, Y.M., Suh, H.J. and Kim, J.M. (2001) Purification and Properties of Extracellular Phytase from Bacillus sp. KHU-10. Journal of Protein Chemistry, 20, 287-292. https://doi.org/10.1023/A:1010945416862

[19] Lineweaver, H. and Burk, D. (1934) The Determination of Enzyme Dissociation Constants. Journal of the American Chemical Society, 56, 658-666. https://doi.org/10.1021/ja01318a036

[20] Ha, N.C., Oh, B.C., Shin, S., Kim, H.J. and Oh, B.H. (2000) Crystal Structures of a Novel, Thermostable Phytase in Partially and Fully Calcium-Loaded States. Nature Structural \& Molecular Biology, 7, 147-153. https://doi.org/10.1038/72421 